\title{
Analisis Penurunan Parameter Pencemar Limbah Cair Laundry dengan Multi Soil Layering (MSL)
}

\author{
Hadrah*, Monik Kasman, Karunia Tri Septiani
}

\author{
Program Studi Teknik Lingkungan Universitas Batanghari \\ *e-mail : hadrah.hasan@gmail.com
}

\begin{abstract}
ABSTRAK
Limbah cair laundry merupakan grey water yaitu bagian dari limbah cair domestik yang proses pengalirannya tidak melalui toilet. Limbah cair laundry mengandung COD, BOD, TSS, Total Fosfat, pH, MBAS yang termasuk turunan zat organik sehingga akumulasinya dapat menyebabkan meningkatnya kandungan organik pada badan air atau air tanah jika tidak diolah terlebih dahulu. Tujuan penelitian ini adalah mengamati pengaruh hydraulic loading rate (HLR) dan lapisan permeabel (zeolit dan kerikil) terhadap efisiensi penurunan pencemar limbah cair laundry. Variasi HLR terdiri atas $5001 / \mathrm{m}^{2}$. hari, $7501 / \mathrm{m}^{2}$. hari dan $10001 / \mathrm{m}^{2}$. hari. Pada penelitian ini, limbah cair laundry dialirkan secara gravitasi ke reaktor MSL berdimensi 15x50x50 cm. Reaktor MSL terdiri atas lapisan impermeable dan lapisan permeabel. Lapisan impermeabel merupakan lapisan yang terdiri atas campuran tanah dan arang dengan rasio $2: 1$, serta lapisan permeabel terdiri atas lapisan kerikil (MSL 1) dan zeolit (MSL 2) berdiameter 0,25 - 0,5 cm. Berdasarkan hasil penelitian, HLR dan media permeabel berpengaruh terhadap penurunan parameter pencemar limbah cair laundry. Penurunan pencemar tertinggi untuk parameter COD, BOD, TSS, Total Fosfat, pH, dan MBAS diperoleh pada HLR 1000 1/m².hari dengan persentase penurunan tertinggi secara berurutan sebesar 95\% pada MSL 1 dan 92\% pada MSL 2. Penurunan konsentrasi pencemaran limbah cair laundry lebih tinggi di MSL 2 (lapisan permeabel zeolit) dibanding dengan MSL 1 (lapisan permeabel kerikil).
\end{abstract}

Kata Kunci: Limbah cair laundry; Multi Soil Layering (MSL); Pencemar.

\section{ABSTRACT}

Laundry wastewater is grey water, which is part of domestic wastewater, which is not through the toilet. Laundry wastewater contains COD, BOD, TSS, Total Phosphate, pH, MBAS which includes derivatives of organic substances so that the accumulation causes an increase in the organic content of water or groundwater. The purpose of this study was to observe the effects of the hydraulic loading rate (HLR) and permeable layer (zeolite and gravel) on the efficiency of decreasing laundry wastewater pollutants. Variations in HLR consist of $500 \mathrm{l} / \mathrm{m} 2$ day, $750 \mathrm{l} / \mathrm{m} 2$ day and $1000 \mathrm{l} / \mathrm{m} 2$ day. In this study, laundry wastewater was introduced gravitationally into the MSL reactor with dimensions of $15 \times 50 \times 50 \mathrm{~cm}$. The MSL reactor consists of impermeable layers and permeable layers. The impermeable layer is a layer consisting of a mixture of soil and charcoal with a ratio of 2: 1, and a permeable layer consisting of layers of gravel (MSL 1) and zeolite (MSL 2) with a diameter of $0.25-0.5 \mathrm{~cm}$. Based on the results of the study, the HLR and permeable media have an effect on the decrease of laundry wastewater pollutant parameters. The highest decrease in pollutants for $C O D, B O D$, TSS, Total Phosphate, $\mathrm{pH}$, and MBAS parameters was obtained at HLR $1000 \mathrm{l} / \mathrm{m}^{2} . d$ with the highest percentage reduction is $95 \%$ at MSL 1 and 92\% at MSL 2. Decreasing pollutant concentration of laundry wastewater is higher in MSL 2 (permeable layer of zeolite) compared to MSL 1 (permeable layer of gravel).

Keywords: Laudry wastewater; Multi Soil Layering (MSL;) Pollutant.

\section{Pendahuluan}

Limbah cair laundry menurut Metcalf \& Eddy (2004) merupakan grey water yaitu bagian dari limbah cair domestik yang proses pengalirannya tidak melalui toilet. Limbah cair usaha laundry mengandung COD, BOD, TSS, fosfat, $\mathrm{pH}$, MBAS yang merupakan suatu turunan zat organik sehingga akumulasinya dapat menyebabkan meningkatnya kandungan organik pada badan air atau air tanah jika tidak diolah terlebih dahulu. Deterjen atau sabun tersusun atas tiga komponen utama terdiri atas surfaktan (sebagai bahan dasar detergen) antara $20-30 \%$, bahan builder (senyawa fosfat) antara $70-80 \%$, dan bahan aditif (pemutih, pewangi) antara 2-
$8 \%$ (Soemirat, 2003). Konsentrasi fosfat yang melebihi $100 \mu \mathrm{g} / \mathrm{L}$ di badan air menyebabkan suatu fenomena eutrofikasi. Kondisi eutrofik, sangat memungkinkan alga dan tumbuhan air berukuran mikro tumbuh berkembang biak dengan cepat. Kondisi ini menyebabkan rendahnya konsentrasi oksigen terlarut bahkan sampai batas nol sehingga kualitas air turun.

Multi Soil Layering (MSL) merupakan salah satu metode yang terbukti efektif dalam pengolahan limbah cair domestik, industri kecil dan leachate (Salmariza et al, 2002; Kasman, 2004; Salmariza, 2012; Kasman et al, 2017). MSL memanfaatkan kemampuan tanah sebagai media utama dengan meningkatkan fungsinya melalui 
struktur tanah untuk menurunkan parameter pencemar limbah cair. Keunggulan dari metode ini adalah mudah dari segi pengoperasian dan pengontrolan, bersifat ramah lingkungan, dan bahan-bahan yang digunakan mudah didapat seperti, tanah andesol yang berasal dari daerah pegunungan, serbuk gergaji, arang kelapa, dan material lain sebagai lapisan anaerob, serta kerikil atau batuan lainnya sebagai lapisan aerob.

Pada penelitian ini, limbah cair usaha laundry yang digunakan pada sampel penelitian ini diolah dengan media permeabel zeolit dan kerikil. Reaktor MSL terdiri atas lapisan impermeabel yaitu campuran tanah, arang dan material organik serta lapisan permeabel yaitu kerikil atau jenis batuan lain. Material yang digunakan dalam instalasi reaktor MSL tersedia melimpah di Indonesia, sehingga sangat direkomendasikan untuk diimplementasikan. Fokus penelitian ini adalah mengamati pengaruh laju pembebanan hidraulis atau hydraulic loading rate (HLR) terhadap penetralan $\mathrm{pH}$ dan efisiensi reduksi pencemar dalam MSL, meliputi COD, BOD, TSS, Phospat, dan MBAS.

\section{Metode Penelitian}

\subsection{Alat dan Bahan}

Reaktor MSL yang akan didesain terbuat dari akrilik dengan dimensi $15 \times 50 \times 50 \mathrm{~cm}$ yang dilengkapi dengan pipa inlet $1 / 2$ inci, pipa outlet $1 / 2$ inci dan pipa aerasi $1 / 2$ inci. Lapisan dasar reaktor MSL adalah batu pecah berdiameter 1-3 $\mathrm{cm}$ dengan ketinggian $5 \mathrm{~cm}$ disusun dan ditutup permukaannya dengan jaring plastik. Lapisan kedua, diisi dengan kerikil/zeolit dengan ketinggian $5 \mathrm{~cm}$. Pada lapisan ketiga dibuat blok campuran tanah yang dipasang sejajar pada jarak masing-masingnya $4 \mathrm{~cm}$. Kemudian lapisan selanjutnya diisi dengan kerikil/zeolit setinggi $3 \mathrm{~cm}$. Lapisan-lapisan lain diisikan dengan cara yang sama sampai membentuk beberapa lapis blok-blok campuran tanah, lalu ditutupi dengan jaring plastik dan di atas jaring plastik tersebut dilapisi dengan lapisan kerikil/zeolit setinggi $3 \mathrm{~cm}$.

Reaktor MSL dengan media permeabel kerikil dan media impermeabel terdiri atas tanah andesol dan arang dengan perbandingan berat $2: 1$. Reaktor MSL dengan media permeabel zeolit dan media impermeabel tanah andesol. Pada reaktor 1 (MSL 1), lapisan batuan kerikil yang digunakan adalah hasil ayakan berukuran 3-5 mm. Penggunaan batu kerikil yang seragam bertujuan untuk mencegah terjadinya penyumbatan. Pemilihan batu jenis kerikil dilakukan karena mudah didapatkan dan tidak memakan banyak biaya dalam pengadaannya, sedangkan pada reaktor 2 (MSL 2), lapisan zeolit yang digunakan berukuran $0,25-0,5 \mathrm{~cm}$. Istalasi reaktor MSL dilengkapi dengan bak penampung leachate baku (inlet) dan bak penampung Limbah Cair Laundry (outlet).

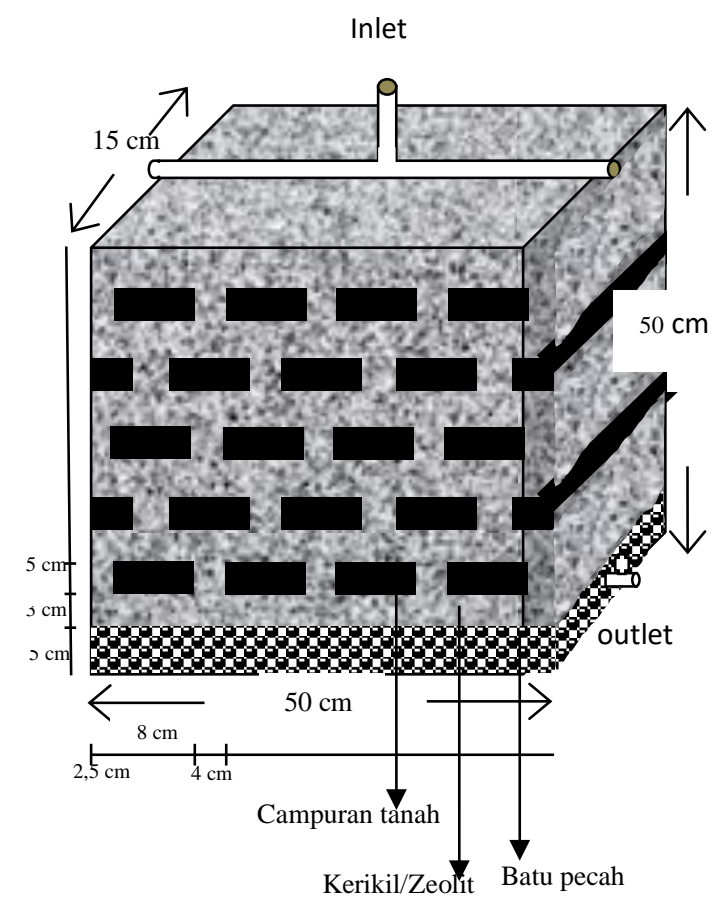

Gambar 1. Reaktor MSL

\subsection{Sampel Limbah Cair Laundry}

Sampel limbah cair laundry yang belum diolah, diperoleh dari bak penampung laundry. Satu kali eksperimen, sampel yang dialirkan ke reaktor MSL adalah 75 liter. Sampel yang diambil disimpan dalam wadah dirigen plastik dan segera digunakan. Karakterisasi awal sampel laundry dilakukan untuk mengetahui besar konsentrasi pencemar yang terdapat dalam laundry yang akan diolah.

Secara fisik, limbah cair usaha laundry keruh berwarna keabu-abuan dan berbau (Gambar 2). Penurunan parameter pencemar sesuai baku mutu Permen LH No. 5 Tahun 2014 tentang Baku Mutu Air Limbah. Perbandingan visual antara limbah cair usaha laundry awal dan hasil olahannya dapat dilihat pada gambar 2.

\subsection{Prosedur}

Pada penelitian ini, kinerja sistem MSL dilihat dengan memvariasikan hydraulic loading rate (HLR) atau laju pembebanan hidrolis yaitu $500 \mathrm{l} / \mathrm{m}^{2}$.hari, 750 $1 / \mathrm{m}^{2}$.hari, dan $10001 / \mathrm{m}^{2}$.hari. Eksperimen untuk tiap HLR dilakukan satu kali dan pengambilan sampel di titik outlet juga dilakukan satu kali. 


\section{Hasil dan Pembahasan}

Reduksi pencemar dalam limbah laundry sangat dipengaruhi oleh komposisi material lapisan yang bisa dilalui oleh cairan (permeable) dan lapisan yang sulit dilalui oleh cairan (impermeable) yang tersusun di dalam reaktor MSL. Efisiensi reduksi dari parameter pencemar dalam leachate sangat dipengaruhi oleh laju alir pembebanan hidraulis (Hydraulic Loading Rate).

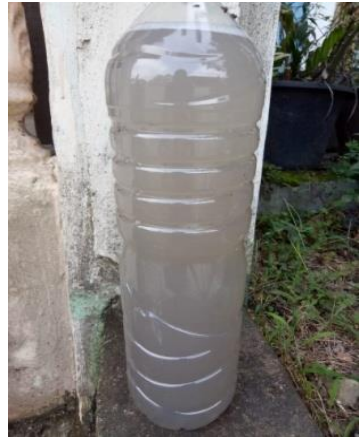

a

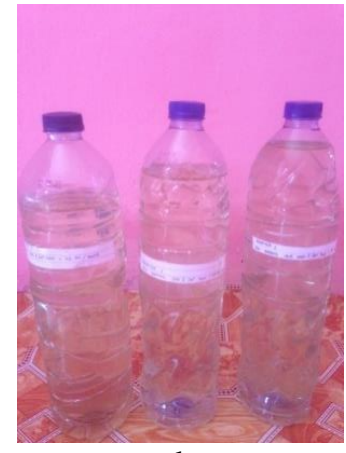

$\mathrm{b}$

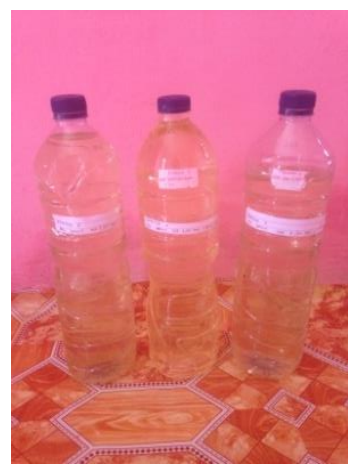

Gambar 2. Sampel limbah cair usaha laundry (a) hasil pengolahan limbah cair usaha laundry (b) dan (c)
Tabel 1. Hasil Uji Awal Limbah Cair Usaha Laundry

\begin{tabular}{cccc}
\hline Parameter & Satuan & $\begin{array}{c}\text { Hasil } \\
\text { Analisis }\end{array}$ & $\begin{array}{c}\text { Baku } \\
\text { Mutu* }\end{array}$ \\
\hline $\mathrm{pH}$ & - & 6,81 & $6,0-9,0$ \\
$\mathrm{BOD}$ & $\mathrm{Mg} / \mathrm{L}$ & 73 & 75 \\
$\mathrm{COD}$ & $\mathrm{Mg} / \mathrm{L}$ & 162 & 180 \\
TSS & $\mathrm{Mg} / \mathrm{L}$ & 68 & 60 \\
Total Fosfat & $\mathrm{Mg} / \mathrm{L}$ & 0,806 & 2 \\
MBAS & $\mathrm{Mg} / \mathrm{L}$ & 1,56 & 3 \\
\hline
\end{tabular}

*Baku Mutu : Permen LH No. 5 Tahun 2014

\subsection{Debit Pengolahan}

Limbah cair usaha laundry dialirkan dengan Hydraulic Loading Rate (HLR) untuk MSL reaktor 1 dan reaktor 2 yaitu $500 \mathrm{l} / \mathrm{m}^{2}$.hari, $750 \mathrm{l} / \mathrm{m}^{2}$.hari, dan $1000 \mathrm{l} / \mathrm{m}^{2}$.hari. HLR adalah laju alir pembebanan hidrolis (HLR) dalam limbah cair usaha laundry terhadap suatu bidang permukaan dalam satuan waktu tertentu. Dalam aplikasinya laju alir pembebanan hidrolis (HLR) digunakan untuk menentukan debit atau beban limbah cair laundry yang akan dialirkan ke reaktor MSL dalam satuan waktu tertentu, misalnya dinyatakan dalam $\mathrm{ml} /$ menit. Secara matematis dapat dinyatakan dalam persamaan berikut:

$\mathrm{Q}_{\text {HLR }}=$ HLR $\mathrm{x}$ Luas bidang permukaan

Pada HLR 500 1// $\mathrm{m}^{2}$.hari, $750 \mathrm{l} / \mathrm{m}^{2}$.hari, dan 1000 $1 / \mathrm{m}^{2}$.hari debit limbah cair laundry secara berurut adalah $26 \mathrm{ml} /$ menit, $39 \mathrm{ml} /$ menit dan $52 \mathrm{ml} /$ menit.

Tabel 2. Hasil uji pengolahan limbah cair laundry dengan MSL

\begin{tabular}{|c|c|c|c|c|c|c|c|c|c|}
\hline & \multirow{3}{*}{ Parameter } & \multirow{3}{*}{ Satuan } & \multirow{3}{*}{$\begin{array}{c}\text { Konsentrasi } \\
\text { Awal }\end{array}$} & \multicolumn{6}{|c|}{ Konsentrasi Akhir } \\
\hline & & & & \multicolumn{3}{|c|}{ MSL 1} & \multicolumn{3}{|c|}{ MSL 2} \\
\hline & & & & HLR 500 & HLR 750 & HLR 1000 & HLR 500 & HLR 750 & HLR 1000 \\
\hline 1. & BOD & $\mathrm{Mg} / \mathrm{L}$ & 73 & 18 & 17 & 11 & 11 & 9 & 9 \\
\hline 2. & COD & $\mathrm{Mg} / \mathrm{L}$ & 162 & 42 & 39 & 21 & 25 & 21 & 21 \\
\hline 3. & TSS & $\mathrm{Mg} / \mathrm{L}$ & 68 & 18 & 10 & 8 & 12 & 11 & 8 \\
\hline 4. & Total Fosfat & $\mathrm{Mg} / \mathrm{L}$ & 0,806 & 0,191 & 0,189 & 0,176 & 0,642 & 0,627 & 0,425 \\
\hline 5. & MBAS & $\mathrm{Mg} / \mathrm{L}$ & 1,56 & 0,098 & 0,096 & 0,080 & 0,235 & 0,213 & 0,127 \\
\hline 6. & $\mathrm{pH}$ & $\mathrm{Mg} / \mathrm{L}$ & 6,81 & 6,37 & 6,36 & 6,33 & 6,24 & 6,73 & 6,19 \\
\hline
\end{tabular}

\subsection{Pengaruh HLR Terhadap Penurunan Parameter Pencemar}

Limbah cair laundry dialirkan secara gravitasi atas ke bawah (gravity downflow system). Eksperimen dilakukan secara batch (non kontinu) dengan HLR 500 1/m².hari, $750 \mathrm{l} / \mathrm{m}^{2}$.hari dan $1000 \mathrm{l} / \mathrm{m}^{2}$.hari. Hasil uji pengolahan limbah cair laundry dengan metoda MSL disajikan pada Tabel 2. 


\section{Penetralan pH}

Limbah cair usaha laundry dimana nilai $\mathrm{pH}$ berkisar 6,81. Nilai pH pada ketiga HLR dan semua proses pengolahan menunjukkan kecenderungan yang sama yaitu netral dan tidak melebihi baku mutu (6-9). Hal ini cenderung disebabkan sifat alami tanah yang mempunyai kemampuan untuk menetralkan $\mathrm{pH}$. Pada MSL 2 media permeabel zeolit dengan variasi HLR $750 \mathrm{l} / \mathrm{m}^{2}$.hari terdapat nilai yaitu 6,73 terlihat lebih baik dalam menyisihkan parameter pencemar laundry pada variasi HLR 750 1/ $/ \mathrm{m}^{2}$.hari MSL 2.

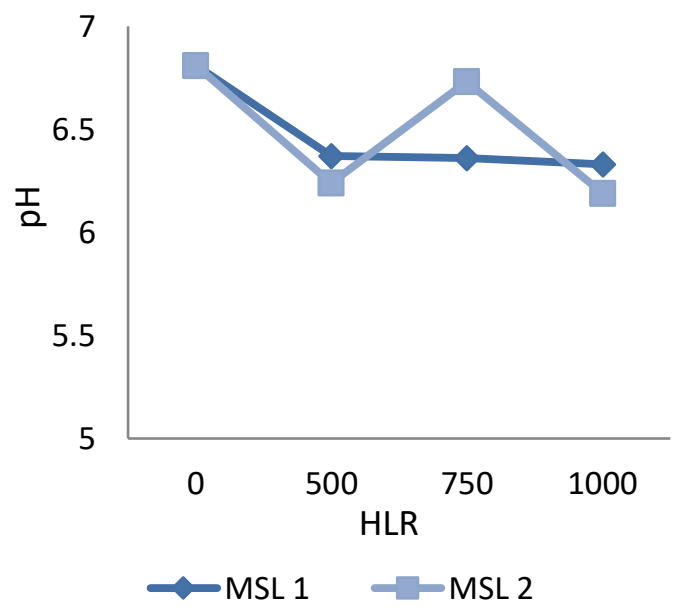

Gambar 3. Pengaruh HLR Terhadap Parameter pH

\section{Efisiensi Penurunan Parameter BOD}

Nilai BOD yang tinggi menunjukkan bahwa terdapat banyak senyawa organik dalam limbah, sehingga banyak oksigen yang dibutuhkan oleh mikroorganisme untuk menguraikan senyawa organik, sedangkan nilai BOD yang rendah menunjukkan terjadinya penguraian limbah organik oleh mikroorganisme.

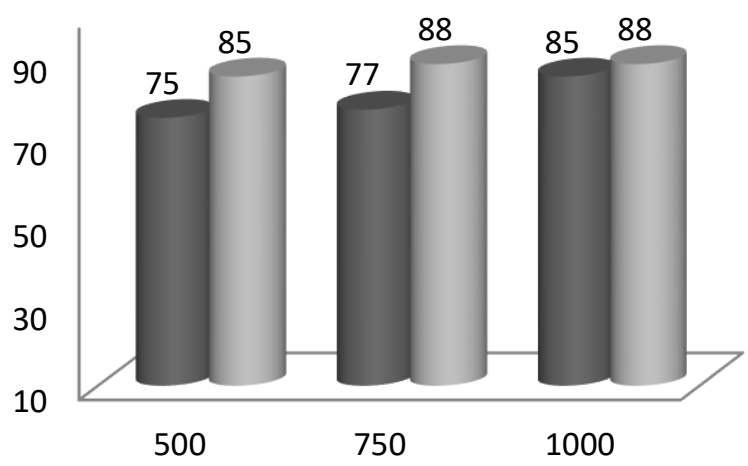

- MSL 1 MSL 2
Gambar 4. Pengaruh HLR terhadap efisiensi Penurunan BOD

\section{Efisiensi Penurunan Parameter COD}

Penurunan nilai COD sesudah pengolahan disebabkan karena di dalam sistem MSL terjadi bermacam-macam proses seperti filtrasi, adsorbsi dan dekomposisi. Penurunan COD lebih membutuhkan kontak yang efektif antara air limbah dengan blok campuran tanah dimana ini mewakili lambatnya dekomposisi zat organik.

Efisiensi penurunan parameter COD pengolahan limbah cair usaha laundry pada HLR 500 1/m².hari, 750 $1 / \mathrm{m}^{2}$.hari, dan $1000 \mathrm{l} / \mathrm{m}^{2}$.hari, MSL 1 (media kerikil, arang dan tanah andesol) persentase penurunan COD terlihat tidak stabil yaitu secara berurut 74\%, 76\%, 74\% sementara, di MSL 2 persentase penurunan COD terlihat stabil yaitu secara berurut $84 \%, 87 \%, 87 \%$.

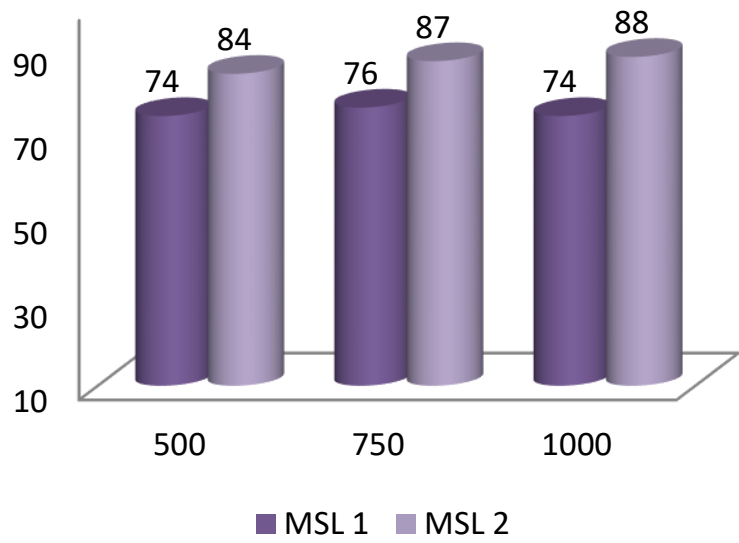

Gambar 5. Pengaruh HLR Terhadap Efisiensi Penurunan COD

Hasil ini sama dengan hasil pada Hikmah (2014) tentang Pengolahan leacheate dengan MSL (media permeabel zeolit dan kerikil). Efisiensi penurunan COD lebih dipengaruhi oleh meningkatnya HLR. Hal ini disebabkan karena dekomposisi COD membutuhkan waktu retensi yang panjang dan waktu retensi menurun sejalan dengan meningkatnya HLR.

Efisiensi Penurunan Parameter TSS 


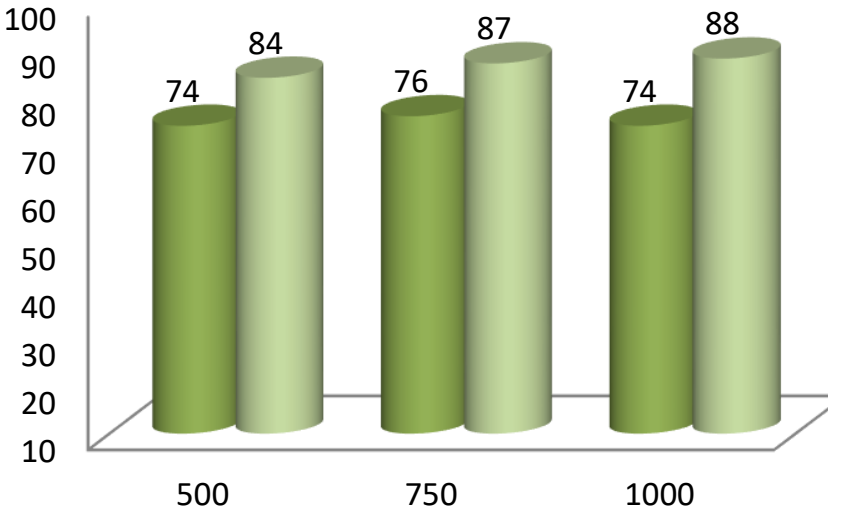

MSL $1 \square$ MSL 2

Gambar 6. Pengaruh HLR terhadap efisiensi penurunan TSS

Penurunan konsentrasi TSS menghasilkan nilai efisiensi penurunan yang baik. Efisiensi penurunan parameter TSS pengolahan limbah cair usaha laundry pada HLR $500 \quad 1 / \mathrm{m}^{2}$.hari, $750 \quad 1 / \mathrm{m}^{2}$.hari, dan 1000 $1 / \mathrm{m}^{2}$.hari, MSL 1 persentase penurunan TSS terlihat tidak stabil yaitu secara berurut $73 \%, 85 \%, 88 \%$ sementara, di MSL 2 persentase penurunan TSS terlihat stabil yaitu secara berurut $82 \%, 84 \%, 88 \%$.

\section{Efisiensi Penurunan Parameter Total Fosfat}

Kandungan Total Fosfat yang tinggi menyebabkan suburnya algae dan organisme lainnya apa yang dikenal dengan eutrophikasi. Eutrophikasi adalah masalah lingkungan hidup yang dapat mengakibatkan kerusakan ekosistem perairan khususnya pada air tawar dimana tumbuhan tumbuh sangat cepat dibandingkan pertumbuhan yang normal.

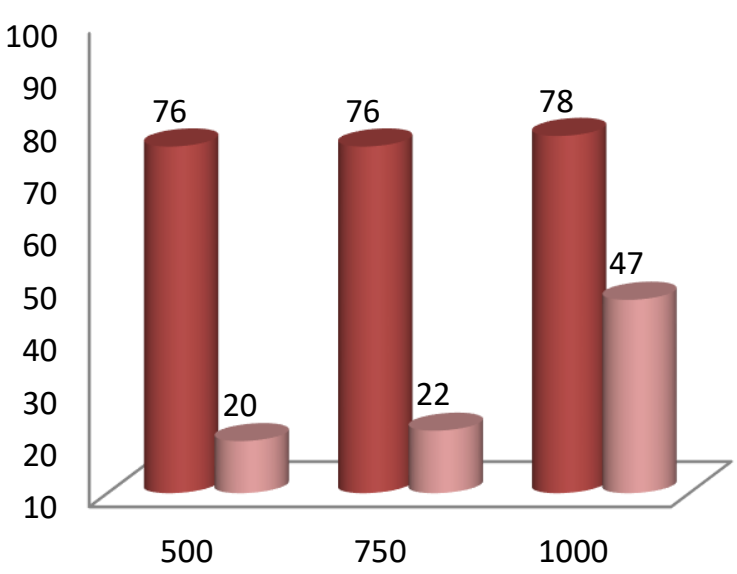

MSL $1 \square$ MSL 2
Gambar 7. Pengaruh HLR terhadap efisiensi penurunan Total Fosfat

Efisiensi penurunan parameter Total Fosfat pengolahan limbah cair usaha laundry pada variasi HLR $500 \mathrm{l} / \mathrm{m}^{2}$.hari, $750 \mathrm{l} / \mathrm{m}^{2}$.hari, dan $1000 \mathrm{l} / \mathrm{m}^{2}$.hari, MSL 1 persentase penurunan Total Fosfat terlihat tidak stabil yaitu secara berurut 76\%, 76\%, 78\% sementara, di MSL 2 persentase penurunan Total Fosfat terlihat tidak stabil yaitu secara berurut 20\%, 22\%, 47\%. Jika dibandingkan kedua MSL tersebut, maka MSL 1 mempunyai persentase penurunan tertinggi.

\section{Efisiensi Penurunan Parameter MBAS}

Penurunan MBAS terjadi pada semua HLR. Hal ini karena adanya mikrooganisme yang terkandung di dalam media tumbuh dan mampu bertahan sehinggaa akhirnya dapat mendegradasi deterjen yang terandung di dalam air (Titisititi, 2010).

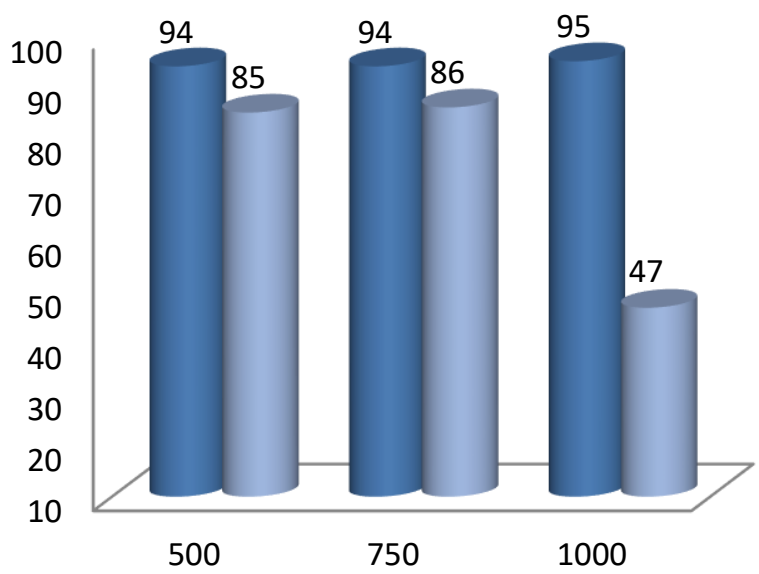

MSL 1 MSL 2

Gambar 8. Pengaruh HLR Terhadap Efisiensi Penurunan MBAS

Efisiensi penurunan parameter MBAS pengolahan limbah cair usaha laundry pada variasi HLR 500 $1 / \mathrm{m}^{2}$.hari, $750 \mathrm{l} / \mathrm{m}^{2}$.hari, dan $1000 \mathrm{l} / \mathrm{m}^{2}$.hari, MSL 1 media permeabel kerikil persentase penurunan MBAS terlihat tidak stabil yaitu secara berurut $94 \%, 94 \%, 95 \%$ sementara, di MSL 2 media permeabel zeolit persentase penurunan phospat terlihat tidak stabil yaitu secara berurut $85 \%, 86 \%, 92 \%$. Efisiensi penurunan MBAS memiliki nilai tertinggi kisaran $85-95 \%$ dibandingkan dengan efisiensi penurunan BOD, COD, TSS, Phospat. 


\section{Kesimpulan}

Dari hasil penelitian yang dilakukan, dapat dikemukakan beberapa kesimpulan sebagai berikut :

1. Berdasarkan penelitian yang dilakukan, variasi HLR sangat berpengaruh terhadap penurunan parameter pencemar limbah cair usaha laundry. Penurunan pencemar tertinggi untuk parameter COD, BOD, TSS, Total Fosfat, pH, dan MBAS diperoleh pada HLR $1000 \quad \mathrm{l} / \mathrm{m}^{2}$.hari dengan persentasi penurunan tertinggi secara berurutan sebesar $95 \%$ pada MSL 1 dan penurunan $92 \%$ pada MSL 2.

2. Hasil uji konsentrasi akhir limbah pada pengolahan menggunakan MSL menunjukkan bahwa penurunan parameter pencemar limbah cair usaha laundry dengan metode media zeolit lebih baik dalam menyisihkan parameter pencemar limbah laundry.baik COD, BOD, TSS, Total Fosfat, $\mathrm{pH}$, dan MBAS.

\section{Daftar Pustaka}

Attanandana, T., B. Saitthiti, S. Thongpae, S. Kritapirom, S. Luanmanee, and T. Wakasutki. (2000). Multy media layering system for food service wastewater treatment: Ecology Engineering, Vol. 15 (2000) pp: 133-138.

Chen, X., Sato, K., Wakatsuki, T., and Masunaga, T. (2007). Effect of structural difference on wastewater treatment efficiency in multi-soil-layering systems: Relationship between soil mixture block size and removal efficiency of selected contaminants. Soil Science and Plant Nutrition, Vol.53, No. 2: pp. 206-214.

Eddy, 2008. Karakteristik Limbah Cair. Jurnal Ilmiah Teknik Lingkungan, Vol.2, No.2, p.20.

Ginting, P. (2007). Sistem Pengelolaan Lingkungan dan Limbah Industri. Bandung: Yrama Widya.

Hikmah, (2014). Reduksi parameter pencemar Dalam leachate dengan Metoda Multi soil layering (MSL). Tugas Akhir, Fakultas Teknik Universitas Batanghari, Jambi.
Hudori, (2008). Pengolahan Air Limbah Laundry dengan Menggunakan Elektrokoagulasi (skripsi). Bandung: Institut Teknologi Bandung.

Kasman, M. (2004). Studi Pengolahan Limbah Cari Industri Keripik Ubi Kayu (Manihot Utilissima) dengan Metoda Multi Soil Layering (MSL). Tugas Akhir, Fakultas Teknik Universitas Andalas, Padang.

Kasman, M., Herawati, P., Hikmah. (2017). Pengolahan Leachate dengan Menggunakan Multi Soil Layering (MSL). Jurnal Ilmiah Universitas Batanghari, 14(3). PISSN 1411-8939, E-ISSN 2549-4236.

Kementeran Lingkungan Hidup. (2014). Peraturan Menteri Lingkungan Hidup RI No.5 Tahun 2014 Tentang Baku Mutu Air Limbah. Jakarta.

Masunaga et al, (2007). Characteristics of Wastewater Treatment Using a Multi Soil Layering System in Relation to Wastewater Contamination Levels and Hydraulic Loading Rate, Soil Science and Plant Nutrition: Japan

Metcalf and Eddy, inc., (2004). Wastewater Engineering: Treatment and Reuse, 4th edition. New York: Mc Graw-Hill.

Putra, A. (2001). Pengolahan Limbah Cair PT. Bumi Sarimas Menuju Air Layak Minum dengan Metoda MSL (Multi Soil Layering) yang Dicampurkan Sekam Padi. Thesis Pascasarjana, Universitas Andalas, Padang.

Salmariza, S., Sofyan, Ahmad, S. (2002). Minimalisasi Pencemaran Industri Crumb Rubber dengan Metoda MSL. Laporan Penelitian, Padang: Baristandag.

Salmariza. (2011). Aplikasi Metoda MSL (Multi Soil Layering) Untuk Mengolah Air Limbah Industri Edilble Oil. Jurnal Riset. Vol.5. No.3. Padang, Sumatera Barat.

Smulders, E. (2002). Laundry Detergents, Wiley-VCH, Veriag $\mathrm{GmbH}$, Weinheim.

Suhardi, (1994). Analisis Bahan Pangan dan Pertanian. Liberty: Yogyakarta.

Syafnil, (2008). Mereduksi Kandungan Fe (Besi) dengan Metode Multi Soil Layering (MSL). Jurnal Gradien Volume 4 Nomor 2 (2008).

Wakatsuki, T, et al. (2001). High Grade On-Site Treatment of Domestic Wastewater and Polluted River Water by Multi Soil Layering Method. Ecological Engineering. Japan: Elsivier Press. 